\title{
A Critical Appraisal on the "Level-of-evidence" Classification Systems
}

\author{
Sachin C Sarode ${ }^{1}$, Namrata Sengupta ${ }^{2}$, Gargi S Sarode ${ }^{3}$, Amol R Gadbail ${ }^{4}$, Shailesh Gondivkar ${ }^{5}$, Shankargouda Patil ${ }^{6}$
}

The Journal of Contemporary Dental Practice (2019): 10.5005/jp-journals-10024-2674

Evidence-based medicine is about analyzing the evidence and then utilizing the same analysis in making clinical decisions. The key element of evidence-based medicine is the hierarchical system of categorizing evidence. This hierarchy is known as the "levels of evidence". . Clinicians use this classification to identify the highest level of evidence to answer clinical questions. Various types of research studies answer the different kinds of clinical questions. ${ }^{1}$

In 1979, the Canadian Task Force on Periodic Health Examination reported the levels of evidence for the first time. ${ }^{1}$ Since the establishment of the classification of the levels, many journals and organizations have modified the classification system according to their needs. The Centre for Evidence-based Medicine (CEBM) based at the Nuffield Department of Primary Care Health Sciences, the University of Oxford has developed and modified the classification of levels. This CEBM system is recognized universally to identify the level of evidence in medical literature. ${ }^{2}$ Level 1 is the highest level of evidence and level 5 the lowest. These levels categorize studies according to the chances of bias. ${ }^{1}$ Systematic review of randomized control trials are placed at the highest level owing to their unbiased study design. Case series and expert opinions (bias of author's views) are ranked the lowest.

Today, many classification systems are available in the literature such as levels of evidence from Sackett on the use of antithrombotic agents, ${ }^{3}$ levels of evidence developed by the American Society of Plastic Surgeons for prognostic studies, and levels of evidence developed by CEBM for treatment (therapeutic studies). These systems are used in studies related to systematic reviews, metaanalysis, and bibliometric analysis. A level-of-evidence analysis is of paramount importance in such study designs, which increases the credibility of the outcome obtained in the articles.

After a careful analysis of the available classification systems, it is observed that they are related to clinical studies. Hence, the level-of-evidence scales is not useful for the following scenarios:

\section{Systematic Reviews, Meta-analysis, or Bibliometric Analysis that are Not Related to Treatments}

Such research papers include studies on histopathology, demographic analysis, epidemiological studies, and biochemical investigations. Even though such studies are directly or indirectly associated with the patients, it is not possible to determine the level of evidence in such studies.

\section{Forensic SCIEnces}

Usually studies in such cases involve victim identification, sex determination, age estimation, bite mark analysis, finger print analysis, etc. It is not possible to use the existing level-of-evidence classifications.
${ }^{1-3}$ Department of Oral Pathology and Microbiology, Dr DY Patil Dental College and Hospital, Dr DY Patil Vidyapeeth, Pimpri, Pune, India

${ }^{4}$ Department of Dentistry, Indira Gandhi Government Medical College and Hospital, Nagpur, Maharashtra, India

${ }^{5}$ Department of Oral Medicine and Radiology, Government Dental College and Hospital, Nagpur, Maharashtra, India

${ }^{6}$ Department of Maxillofacial Surgery and Diagnostic Sciences, Division of Oral Pathology, College of Dentistry, Jazan University, Jazan, Kingdom of Saudi Arabia

Corresponding Author: Sachin C Sarode, Department of Oral Pathology and Microbiology, Dr DY Patil Dental College and Hospital, Dr DY Patil Vidyapeeth, Pimpri, Pune, India, Phone: +91 9922491465, e-mail: drsachinsarode@gmail.com

How to cite this article: Sarode SC, Sengupta N, et al. A Critical Appraisal on the "Level-of-evidence" Classification Systems. J Contemp Dent Pract 2019;20(8):879.

Source of support: Nil

Conflict of interest: None

\section{In Vitro Studies}

Studies that involve the testing of material strengths of implants, restorations, prosthesis etc. is not eligible for the level-of-evidence analysis.

\section{Laboratory Preclinical Studies}

These are based on the cell-lines-related experimentations. Such studies cannot come under the purview of the level-of-evidence analysis.

\section{Animal Studies}

Although drug trials on animals are considered as clinical studies, currently there are no level-of-evidence scales designed for such studies.

Looking at these aspects, it is the need of hour to design, develop, and validate appropriate classification systems for measuring the level of evidence for the aforementioned scenarios. Such kinds of scales will definitely improve the credibility and standard of the outcomes obtained through systematic reviews, meta-analysis, or bibliometric analysis on non-clinical studies.

\section{References}

1. Burns PB, Rohrich RJ, et al. The levels of evidence and their role in evidence-based medicine. Plastic and reconstructive surgery 2011;128(1):305. DOI: 10.1097/PRS.0b013e318219c171.

2. Moriarity A, Kennedy J, et al. Levels of evidence in the treatment of slipped capital femoral epiphysis: a systematic review. Orthopedic reviews 2016;8(2):6303. DOI: 10.4081/or.2016.6303.

3. Sackett DL. Rules of evidence and clinical recommendations on the use of antithrombotic agents. Chest 1989;95:2S-4S. DOI: 10.1378/ chest.95.2_Supplement.2S.

(C) The Author(s). 2019 Open Access This article is distributed under the terms of the Creative Commons Attribution 4.0 International License (https://creativecommons. org/licenses/by-nc/4.0/), which permits unrestricted use, distribution, and non-commercial reproduction in any medium, provided you give appropriate credit to the original author(s) and the source, provide a link to the Creative Commons license, and indicate if changes were made. The Creative Commons Public Domain Dedication waiver (http://creativecommons.org/publicdomain/zero/1.0/) applies to the data made available in this article, unless otherwise stated. 